\title{
Co-existent total anomalous pulmonary venous drainage into portal vein, drainage of left-sided inferior vena cava into left atrium, and splenic agenesis
}

\author{
C. S. MUIR AND K. PRATHAP \\ From the Department of Pathology, University of Singapore, General Hospital, Singapore 3
}

Total anomalous drainage of the pulmonary veins into the portal venous system is rare. Burroughs and Edwards (1960) noted 17 such cases in the 188 examples of total anomalous pulmonary venous drainage which they collected from the literature.

Rarer still is the presence of a left-sided inferior vena cava emptying into the left atrium or into the left side of a common atrium. We have traced five such cases.

A review of the literature by Gilbert, Nishimura, and Wedum (1958) revealed only 81 cases of coexistent splenic agenesis and cardiac malformation. In three of these the pulmonary veins drained into the portal circulation.

The simultaneous presence of all three congenital abnormalities-total anomalous drainage of the pulmonary veins into the portal system, drainage of a left-sided inferior vena cava into the left atrium, and splenic agenesis-must be exceedingly rare. We report such a case, the like of which we have not been able to trace.

\section{CASE REPORT}

T.C. H., a 27-day-old Chinese male infant, was admitted to the General Hospital, Singapore, on 2 May 1964 with a one-week history of breathlessness and cough. He was found to be generally cyanosed: a systolic murmur was heard all over the praecordium, and a few crepitations and wheezes were heard in the lungs. The child died four days after admission. Although congenital heart disease was diagnosed, the nature of the defects was in doubt.

NECROPSY The heart measured $4.5 \mathrm{~cm}$. from base to apex; the transverse diameter was $3.8 \mathrm{~cm}$. It was unusually mobile as the intrapericardial portions of the pulmonary veins were absent. Externally, the two atria and their appendages were clearly defined, but there was no interventricular groove.
Internally, the heart was seen to consist of two incompletely separated atria and a single common ventricle. The cavity of the left atrium was slightly larger than that of the right. The interatrial septum was incomplete, being represented by a small biconcave dense band of tissue, $0.5 \mathrm{~cm}$. in width at either end and $0.2 \mathrm{~cm}$. in width at the centre, running anteroposteriorly and almost vertically (Figs 1 and 2). This was attached superoanteriorly to the atrioventricular junction and inferoposteriorly to the most inferior portion of the atrial walls. There were thus two elliptical interatrial foramina; one, of the ostium secundum type, $1.8 \times 1.1 \mathrm{~cm}$., and a smaller one, of the ostium primum type, $1.5 \times 0.8 \mathrm{~cm}$. (Fig. 1).

The right atrium received a right superior vena cava but no inferior vena cava. In the most inferior portion of the medial wall was a small valveless circular opening $0 \cdot 2 \mathrm{~cm}$. across, into which drained several very small venous channels, which arose from the region of the right atrioventricular groove.

The left atrium received a left superior vena cava and left-sided inferior vena cava (Fig. 1). At the junction of the smooth endocardium with the musculi pectinati were several small openings, the largest 0.2 $\mathrm{cm}$. across (Fig. 1). Neither left nor right superior venae cavae received veins from the surface of the heart, nor was there any communication between them.

There was a single atrioventricular orifice, guarded by three cusps, leading into a common ventricle. The columnae carnae were prominent. There were two stout papillary muscles as well as several smaller ones. The aorta and pulmonary artery arose from the common ventricle anteriorly, the orifices being guarded by tricuspid and bicuspid semilunar valves respectively.

The pulmonary artery, $0.7 \mathrm{~cm}$. in diameter, arose dorsal and to the left of the aorta, bifurcating $2 \cdot 0 \mathrm{~cm}$. from its origin into right and left pulmonary arteries. There was no ductus arteriosus. The right pulmonary artery gave off a small branch (Fig. 3) to the region of the carina which supplied the trachea and bronchi.

The aorta, $1.0 \mathrm{~cm}$. in diameter at its origin, was ventral and to the right of the pulmonary artery; its 


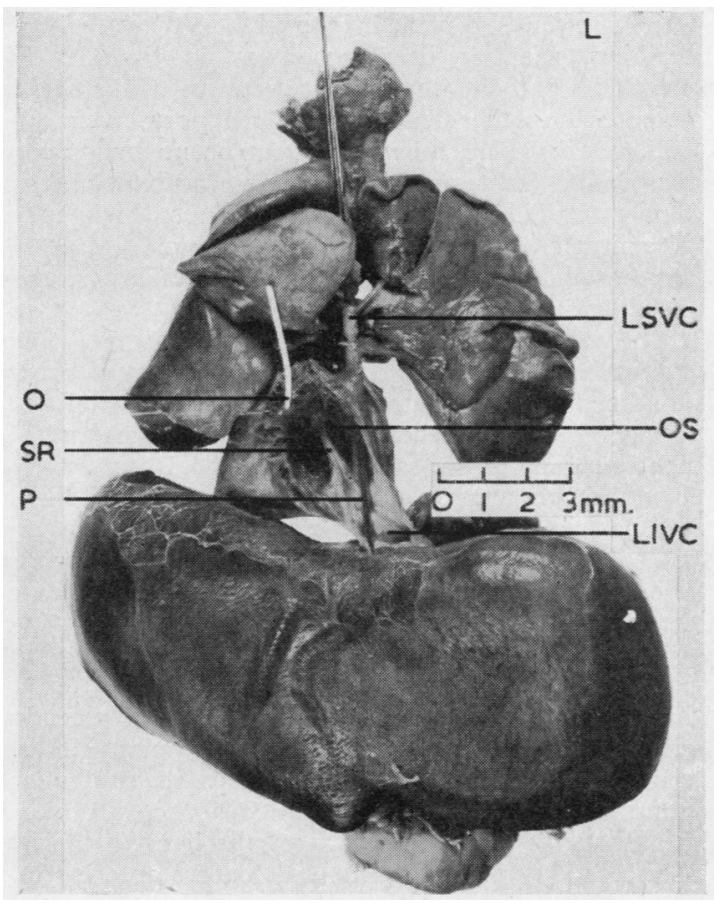

FIG. 1. Anterior view of necropsy specimen after fixation, with heart pulled over to the right and left atrium opened. A silver probe, passed through the superior vena cava, crosses the left atrium to enter the left inferior vena cava. The white plastic probe indicates the opening of $a$ ? enlarged Thebesian vein. LIVC=left inferior vena cava; $L S V C=$ left superior vena cava; $O=$ opening of ? Thebesian vein ; $O S=$ ostium secundum ; $P=$ silver probe ; $S R=$ septal remnant.

subsequent course was normal. The great vessels of the neck appeared normal. Right and left coronary arteries arose behind the right anterior and left posterior aortic cusps. The former passed down the common ventricle towards the apex about $1 \mathrm{~cm}$. from the left border, a major branch running in the right atrioventricular groove. The latter passed in the left atrioventricular groove towards the apex of the heart posteriorly, lying about $1 \mathrm{~cm}$. from the left border of the heart.

Four pulmonary veins from the right lung, and two from the left, united to form short, broad, main pulmonary veins, which joined to form a $\mathrm{T}$-shaped common pulmonary vein, $0.5 \mathrm{~cm}$. in diameter and $4.5 \mathrm{~cm}$. long (Fig. 3). Lying ventral to the oesophagus, and dorsal to the pericardium and the base of the heart, this common pulmonary vein ran caudally, dorsal and to the right of the inferior vena cava, to pierce the diaphragm with the oesophagus, continuing as a grossly dilated left gastric vein which drained into the portal vein (Fig. 3).

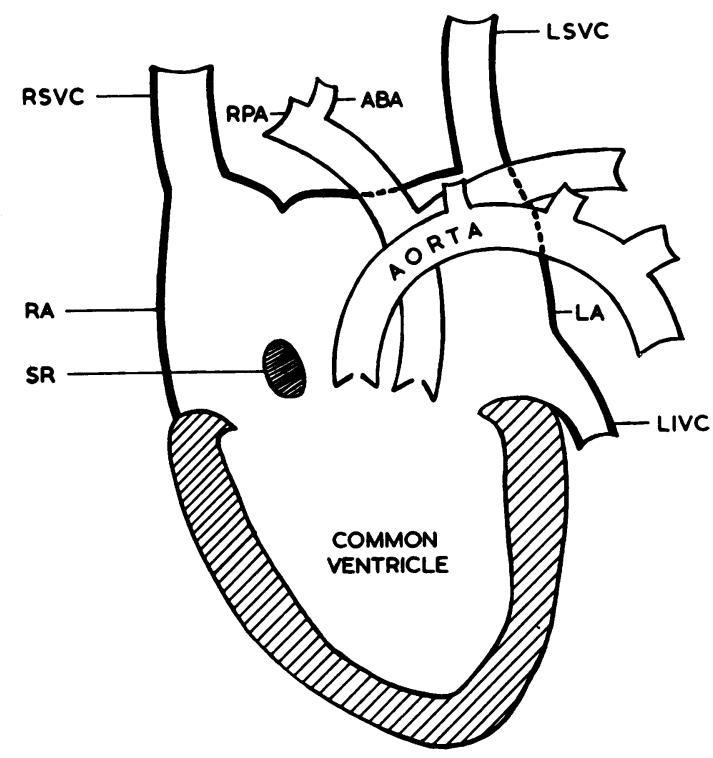

FIG. 2. Diagram illustrating anomalies seen in Fig. 1.

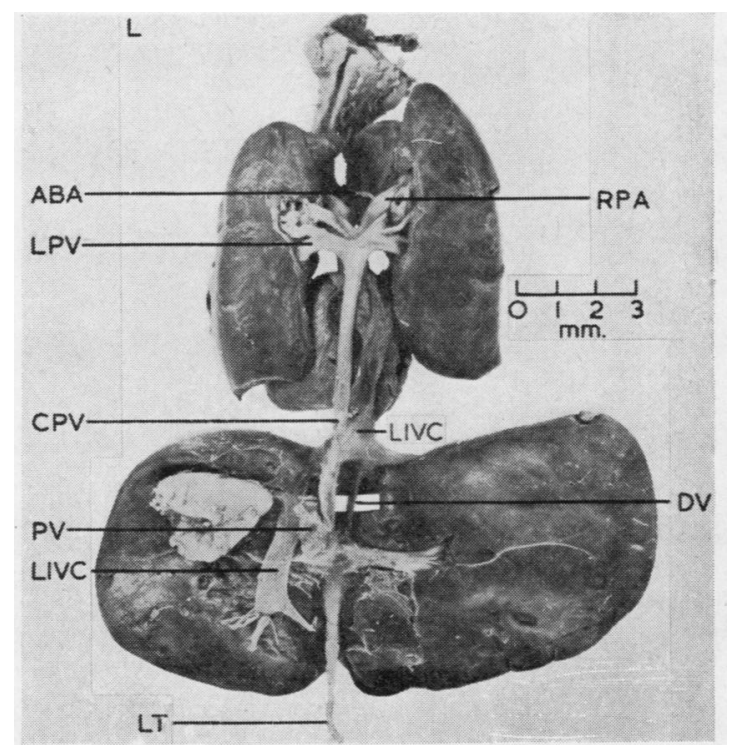

FIG. 3. Specimen viewed from behind with stomach, duodenum, gall bladder, and caudate lobe of liver removed. $A B A=$ aberrant bronchial artery; $C P V=$ common pulmonary vein : $D V=$ ductus venosus; $L I V C=$ left inferior vena cava; $L P V=$ left pulmonary vein; $L T=$ ligamentum teres; $P V=$ portal vein; $R P A=$ right pulmonary artery. 


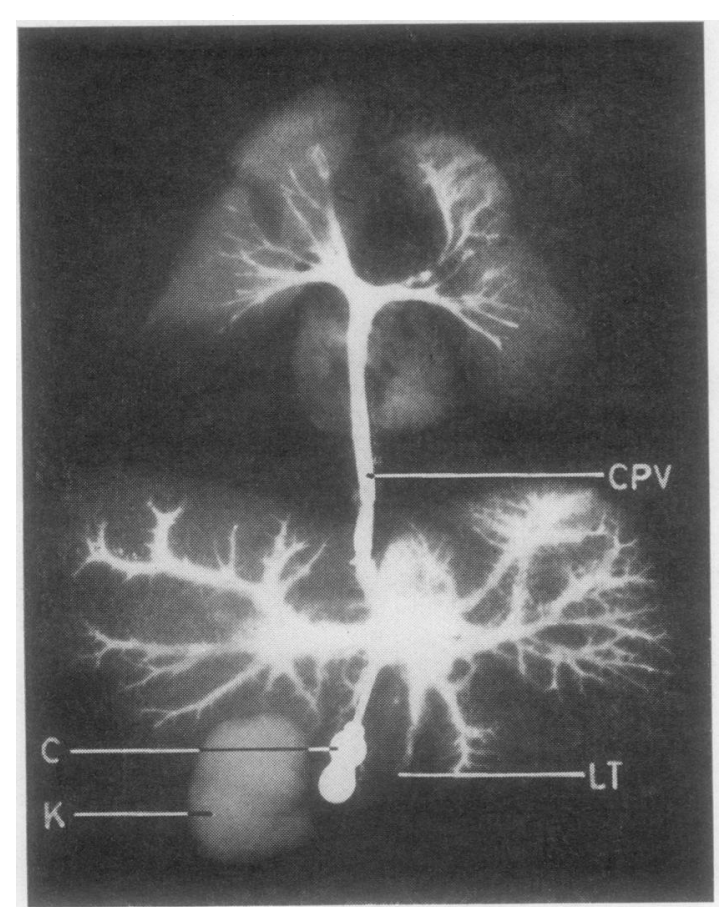

FIG. 4. Portal venogram of necropsy specimen showing cannula in portal vein. There is filling of the branches of the portal vein and retrograde filling of the pulmonary venous system. $C=$ cannula; $C P V=$ common pulmonary vein ; $K=$ left kidney ; $L T=$ ligamentum teres.

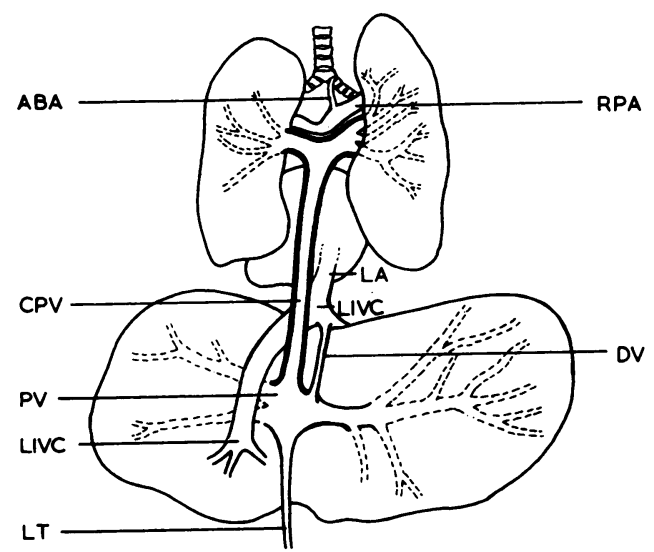

FIG. 5. Diagram illustrating anomalies seen in Fig. 4.

The portal vein, $2.5 \mathrm{~cm}$. long and $2.0 \mathrm{~cm}$. in diameter, received the splenic vein from the midpoint of the pancreas, the superior mesenteric vein, and the umbilical vein, the proximal part of which was patent. This latter vessel entered a tunnel in the liver substance which lay to the left of the gall- $\overrightarrow{\vec{F}}$ bladder (this has been cut away in Fig. 3). The proximal half of the ductus venosus (Fig. 3) was patent; the other half, nearest the portal vein, was $\frac{\bar{\sigma}}{\bar{D}}$ obliterated. There thus seemed to be no major com- $\frac{D}{\sqrt{D}}$ munication between the portal vein and the inferior $\stackrel{\mathbb{D}}{\varrho}$ vena cava. This impression was confirmed by injection of contrast medium into the portal vein (Fig. 4). We have tried to make the anatomical details clearer in $\vec{\circ}$ the diagram (Fig. 5).

The mesenteric artery arose from the aorta. giving $\vec{\omega}$ off the hepatic artery $1.0 \mathrm{~cm}$. from its point of origin. The hepatic artery passed anterior to the portal vein, $\vec{x}$ giving off two branches, the gastro-duodenal and the right gastric. At the same level as the latter vessel a $\omega$ third branch arose which looped round the dilated in left gastric vein as it entered the portal vein and $\triangle$ passed posteriorly to enter the head of the pancreas. 음 The cystic artery and the left and right branches of the hepatic artery appeared normal.

The inferior vena cava, formed by the union of the right and left common iliac veins, lay to the left of the vertebral column and, in this position, ascended $\vec{\varphi}$ vertically. It was joined by a short left renal vein and $\mathrm{cr}$ a long $(5.5 \mathrm{~cm}$.) right renal vein. In its subsequent $\square$ intra-abdominal course it occupied a deep groove in the substance of the left lobe of the liver to the left of the caudate lobe (Fig. 3). Just before entering this groove it received right and left adrenal veins, the right being longer than the left. Having received the $\varrho$ hepatic veins the inferior vena cava pierced the $\overrightarrow{\bar{O}}$ diaphragm to enter the middle mediastinum, traversed $\frac{0}{3}$ the fibrous pericardium and terminated in the lower part of the left atrium. No trace of a right inferior vena cava could be found.

The left lung had three lobes; the right had an incompletely formed fourth lobe, composed of the 음 superior portion of the inferior lobe.

The stomach, duodenum, and pancreas were transposed but were otherwise normal. The small bowel. mesentery was normal. The caecum and ascending colon were freely mobile, but the descending and sigmoid colons were incompletely fused to theo posterior abdominal wall.

The liver was enlarged: it was not inverted. The groove for the inferior vena cava was on the left side of the caudate lobe (Fig. 3). The gall-bladder was normally situated, and the biliary passages were alt $\mathrm{N}$ patent. The spleen was absent and no accessory으 spleniculi could be found. The kidneys and adrenalsw were more cephalic than usual.

All other organs were normal.

HISTOLOGY The hepatic portal tracts were generally黑 enlarged. Although the hepatic arteries and bile ducts appeared normal, the walls of the portal veins weresome two to three times their normal thickness. This was due to the presence of dense collagen admixed $\frac{\rho}{\Phi}$ with smooth muscle. The central veins were promi- $\varrho$ nent; they, too, showed some mural fibrous thickening. The hepatic sinusoids were engorged with red 


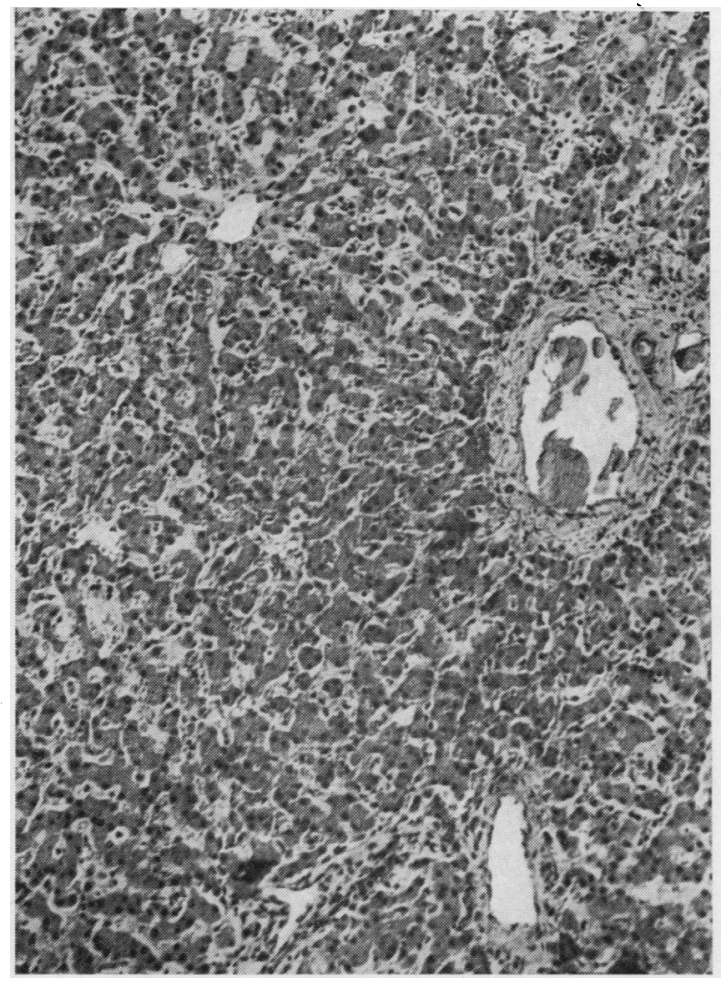

FIG. 6

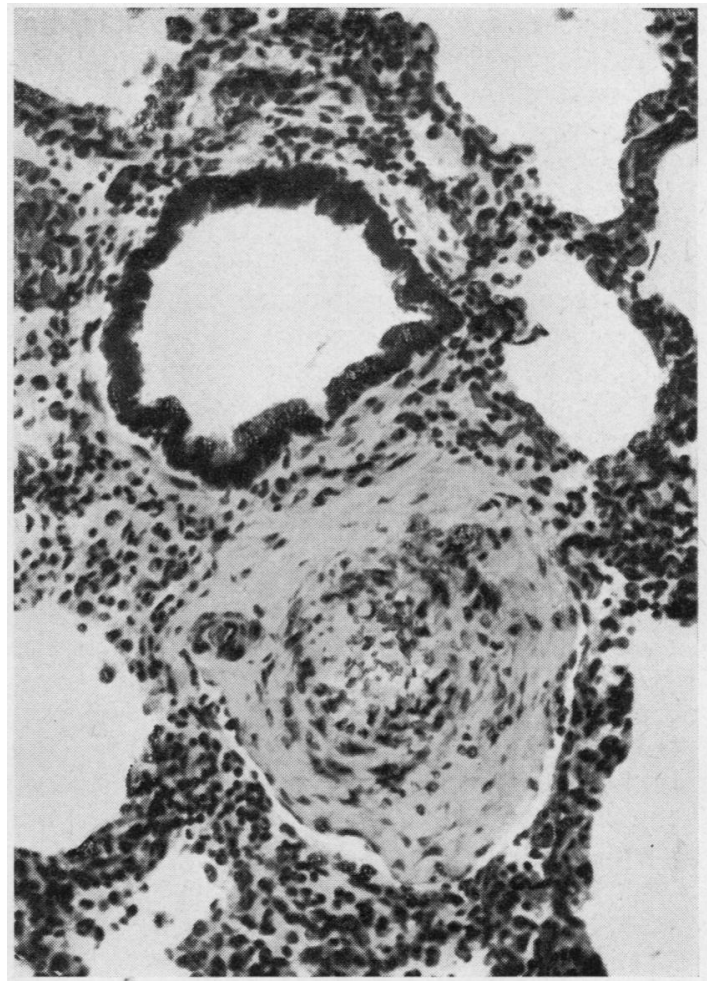

Frg. 7

Fig. 6. Photomicrograph of section of liver. The central veins are prominent, the hepatic sinusoids are engorged with red blood cells, and the thick-walled portal vein (right centre) contains injection material in its lumen. H. \& E. $\times 75$.

FIG. 7. Photomicrograph of section of lung. The thick-walled muscular artery has a lumen to vessel wall ratio of $1: 1$; the alveolar walls are thickened. $H$. and $E . \times 150$.

blood cells (Fig. 6). The Kupffer cells and hepatic parenchymal cells appeared normal. A few foci of extramedullary haemopoiesis were present.

The lungs showed thickening of the alveolar walls. There was considerable intimal proliferation of the elastic arteries. The muscular arteries and arterioles had thick walls, the ratio of lumen to vessel wall being 1:1 (Fig. 7). The pulmonary veins appeared normal.

All other organs seemed normal.

\section{DISCUSSION}

With the rapid progress of cardiovascular surgery and associated improvements in anaesthesia, many complicated cardiovascular anomalies are becoming amenable to surgical correction. The early and accurate diagnosis of such conditions is thus no longer of academic interest. The diagnosis of anomalous pulmonary venous drainage is a matter of urgency, for, as Hughes and Rumore (1944) stated, 'anomalous venous drainage of greater than 50 per cent. of the lungs is not compatible with life to adulthood'. In those with infracardiac connexion of the pulmonary venous drainage, life is usually much shorter - a matter of weeks or even days (Butler, 1952 ; Darling, Rothney, and Craig, 1957 ; Laurence and Brown, 1960). The first step towards diagnosis is to be aware of the existence of such defects, no matter how rare they may be.

Several features of this case are worthy of comment.

ANOMALOUS PULMONARY VENOUS RETURN Although the first instance of abnormal disposition of the pulmonary veins was described by Winslow as long ago as 1739, it was not until 1950 that the first case was diagnosed clinically by cardiac 
catheterization studies (Friedlich, Bing, and Blount, 1950). There are now several reports of successful surgical correction.

Darling et al. (1957) classified total anomalous pulmonary venous connexions into four types: type 1 , the most frequent, in which drainage is into the superior vena caval system (supracardiac connexion); type II, with drainage directly into the coronary sinus or the right atrium (cardiac connexion); type III, where the connexion is below the diaphragm (infra-cardiac connexion); and type IV, in 'which connexions are at more than one anatomical level. Butler (1952) recognized two types of anomalous drainage of the pulmonary veins into the portal venous system: type $A$, in which the common pulmonary vein pierces the diaphragm separately from the oesophageal hiatus and joins the left branch of the portal vein via, or close to, the still-patent ductus venosus; and type $B$, where the common pulmonary vein accompanies the oesophagus to pierce the diaphragm via the oesophageal hiatus before joining the portal vein via a grossly dilated left gastric vein. The drainage in the present case corresponds to Butler's type B.

In defects of Butler's type A, while the pulmonary venous return to the heart is by a devious route, the presence of a patent ductus venosus permits the blood to by-pass the liver. In type B defects the oxygenated blood must perforce pass through the liver to gain the hepatic veins and hence the heart. In such circumstances a shunt might well develop. However, a post-mortem portal venogram (Fig. 4) of our specimen showed filling of the portal vein, its right and left branches, and their finer ramifications, as well as retrograde filling of the left gastric and pulmonary veins. No major intrahepatic venous shunt could be demonstrated. The thickened dilated portal veins (Fig. 6) and the increase of fibrous tissue around the prominent central veins were probably due to a greatly increased blood flow and, possibly, a raised pressure.

In the 3-day-old infant with a type B anomaly described by Laurence and Brown (1960), oesophageal varices sufficiently large to cause haematemesis were noted. The oesophageal veins in our case seemed normal.

As recorded earlier, we were impressed by the abnormal mobility of the heart, which could be freely lifted upwards and forwards on its pedicle because the left atrium was not anchored by the pulmonary veins. This important point, first pointed out by Darling et al. (1957), was stressed by Keith, Rowe, and Vlad (1958) and by Laurence and Brown (1960).
Butler (1952) suggested an embryological $\overrightarrow{\vec{F}}$ explanation for type B defects based on the hypo-o thesis of a dual origin of the pulmonary veins, i.e., 등 from the heart and from the foregut venous plexus (Auër, 1948).

ANOMALIES OF THE INFERIOR VENA CAVA Major anomalies of the inferior vena cava have been $\vec{O}$ infrequently reported. Five examples of a left- $\overrightarrow{\vec{\omega}}$ sided inferior vena cava draining into the left $\stackrel{\sigma}{\omega}$ atrium or into the left side of a common atrium $\overrightarrow{\vec{*}}$ are recorded in the literature (Martin, 1826 ; Pernkopf, 1926; Töndury, 1936; Gouley and $O$ Gilbert, 1939; Leikin, 1951); all had other $\omega$ associated cardiovascular anomalies and all died of within six months of birth.

Martin (1826), describing the first recorded case of splenic agenesis associated with cardiac mal- $\vec{z}$ formation, noted the presence of a persistent left $\underset{\infty}{0}$ superior vena cava and a left inferior vena cava $\overrightarrow{-}$ emptying into the left side of the single atrium. \& Pernkopf (1926) and Töndury (1936) each described a case of multiple congenital anomalies, where the inferior vena cava opened into the left atrium. Gouley and Gilbert's (1939) report concerned a negro girl who died on the ninth day of life. Necropsy showed a persistent ostium primum, $\stackrel{\triangle}{\triangle}$ a left-sided inferior vena cava draining into the $\overrightarrow{\vec{B}}$ left atrium, and hepatic veins emptying directly 3 into the right atrium. Leikin (1951) reported a case $\supset$ where the left atrium received a persistent left superior vena cava, a left inferior vena cava, and two large hepatic veins. We believe that ours is the 으 sixth recorded case of a left-sided inferior vena $\underset{\times}{\stackrel{0}{*}}$ cava draining into the left atrium or the left side $\frac{0}{\sigma}$ of a single atrium.

Drainage of the inferior vena cava into the left 8 atrium per se is not incompatible with longer $₹$ survival (Gardner and Cole, 1955; Meadows, 을 Bergstrand, and Sharp, 1961 ; Venables, 1963). Gardner and Cole (1955) described a woman with cyanotic congenital heart disease who led an active life and underwent repeated pregnancies until her $\sigma$ sudden death at the age of 32 years. The only $N$ defect detected at necropsy was a congenital ్ㅣ abnormality of the proximal (hepatocardiac) seg- $O$ ment of the inferior vena cava, which drained into the left side of the heart instead of the right. The $\frac{\mathbb{D}}{\sim}$ abdominal part of the inferior vena cava was on $\stackrel{?}{+}$ the right side. In the cases recorded by Meadows 0 et al. (1961) and by Venables (1963) the diagnosis $\bar{O}$ was made clinically in each case with the aid of $\stackrel{\mathbb{D}}{\circ}$ cardiac catheterization studies. Their patients, a $\stackrel{\mathbb{D}}{\mathbb{D}}$ negro man aged 37 years and a 9-year-old Australian girl respectively, were alive at the time of publication. 
When one considers the complex development of the inferior vena cava in the embryo from symmetrical venous systems, it is indeed surprising that major anomalies have not been described more frequently.

SPLENIC AGENESIS But one year after Winslow's account of the abnormal disposition of the pulmonary veins Pohl (1740) recorded the first detailed description of splenic agenesis. Martin (1826) described the first case of congenital malformation of the heart and great vessels in an infant with splenic agenesis. Gilbert, Nishimura, and Wedum (1958) collected 81 cases of this combination from the literature ; 41 of these cases had transposition of the stomach as well. Polhemus and Schafer $(1952,1955)$, surveying the literature, observed 'a definite syndromic occurrence of absent spleen, persistent atrioventricularis communis, accessory lobes of the lung, partial situs inversus of the abdominal viscera and anomalies of major blood vessels'; all five features were present in our case.

Putschar and Manion (1956) found three cases of splenic agenesis (including one of their own) in which there was total anomalous pulmonary venous drainage into the portal venous system. The first of these, recorded by Arnold (1868), showed among other defects dextrocardia with right-sided aorta, atresia of the pulmonary artery, and transposition of the atria and systemic veins. Their own case had a four-chambered heart with atrial and ventricular septal defects and a normal pulmonary artery and aorta; the left atrium received a persistent left superior vena cava and an inferior vena cava, and a large right hepatic vein entered the right atrium. The third case, described by $\mathrm{Hu}(1929)$, presented many features similar to those of our patient. His patient was also a male Chinese infant with cor triloculare biatriatum, transposition of the large vessels with a hypoplastic pulmonary artery, patent ostium primum and ostium secundum, a three-lobed left lung, absent ductus arteriosus, total anomalous pulmonary venous drainage into the portal vein via the left gastric vein, persistent left superior vena cava, and a coronary sinus emptying into the left atrium, in addition to absence of the spleen. In his case, however, the inferior vena cava drained into the right atrium, and there was situs inversus of all the abdominal organs, including the liver and colon.

Though congenital heart disease was diagnosed clinically in our case, splenic agenesis was not suspected. Heinz (1890) first observed certain inclusion bodies in erythrocytes, which now bear his name. Their relation to the spleen was recognized by Schilling-Torgau (1912) and by Zadek and Burg (1930). Gasser and Willi (1952) were the first to make the clinical diagnosis of splenic agenesis in infants with congenital heart disease on the basis of the presence of numerous erythrocytes containing Heinz bodies. It is known that Heinz bodies also occur, in the presence of an intact spleen, in persons with toxic haemolytic anaemia caused by chemicals (Freifeld, Schilowa, and Ludwinowsky, 1937), but if such an anaemia can be excluded the diagnostic value of these inclusion bodies lies in the fact that they are constantly present in $10 \%$ or more of the erythrocytes in the peripheral blood of mature newborn infants with agenesis of the spleen. Splenic agenesis and a number of other commonly associated anomalies may be detected if peripheral blood studies are made on every baby with obscure congenital heart disease (Polhemus and Schafer, 1955; Putschar and Manion, 1956). Gilbert et al. (1958) discuss the aetiology of this anomaly. Muir (1959) has described a further seven cases of splenic agenesis in Singapore.

PERSISTENT LEFT SUPERIOR VENA CAVA While drainage of a persistent left superior vena cava into the right atrium via the coronary sinus is not uncommon, termination in the left atrium is (Edwards, 1960). Edwards states, on good developmental grounds, 'whenever the left superior vena cava joins the left atrium, or the left side of a common atrium, the coronary sinus is absent'. In our case, a small opening, draining a small portion of the surrounding heart, was present in the anatomical site of the coronary sinus. Hu (1929) recorded the separate entry of a coronary sinus, and of a persistent left superior vena cava into the left atrium. The large opening in the left atrium (Fig. 1) probably represents an enlarged Thebesian vein.

ANOMALOUS BRONCHIAL ARTERY The origin of the bronchial arteries can be very variable. Cauldwell, Siekert, Lininger, and Anson (1948) made a detailed study of the bronchial arteries in 150 cadavers and described nine basic types, but there was not a single instance of a bronchial artery arising from the pulmonary artery. In certain pathological conditions vessels larger than capillaries are known to connect the bronchial and pulmonary arteries, but we are unable to find any recorded case of a sizable bronchial artery arising from the pulmonary artery, as in our case.

In the early embryo the developing foregut and the respiratory diverticulum are supplied by seg- 
mental branches of the dorsal aorta. Later, with the development of the pulmonary vessels, anastomoses are established between the systemic and pulmonary arterial systems (Tobin, 1952). It is suggested that an abnormal development of the pulmonary arterial end of the anastomosis instead of the systemic arterial end could have resulted in the vessel described.

ABSENT DUCTUS ARTERIOSUS Absence of the ductus arteriosus has been recorded by Stölker (1864), Myers and Keith (1926), Hu (1929), Taussig (1947), and Edwards (1960), associated with major communications between the systemic and pulmonary circulations, as in the present case. Edwards (1960) has suggested an explanation for this anomaly.

\section{SUMMARY}

A rare, possibly unique, combination of congenital defects, viz., total anomalous drainage of the pulmonary veins into the portal venous system via a grossly dilated left gastric vein; drainage of a left-sided inferior vena cava into the left atrium; cor triloculare biatriatum, with ostium primum and ostium secundum atrio-septal defects ; transposition of the great vessels; absent ductus arteriosus; persistent left superior vena cava draining into the left atrium ; origin of a bronchial artery from the pulmonary artery; transposition of the stomach, duodenum, and pancreas; and splenic agenesis, occurring in a 1-month-old Chinese male infant, is described and the relevant literature is reviewed.

We wish to thank Professor K. Shanmugaratnam and Drs. E. B. La'Brooy and M. A. Thomas for useful suggestions and criticism. The patient was under the care of Dr. Quah Quee Guan. Messrs. L. S. Chia and T. C. Tan took the photographs, Mr. J. Nalpon assisted with the portal venogram, and Miss C. N. Tan typed the script.

\section{REFERENCES}

Arnold, J. (1868). Ein Fall von Cor triloculare biatriatum, Communication der Lungenvenen mit der Pfortader und Mangel der Milz. Virchows Arch. path. Anat., 42, 449.

Auër, J. (1948). The development of the human pulmonary vein and its major variations. Anat. Rec., 101, 581 .

Burroughs, J. T., and Edwards, J. E. (1960). Total anomalous pulmonary venous connection. Amer. Heart J., 59, 913.

Butler, H. (1952). An abnormal disposition of the pulmonary veins. Thorax, 7, 249.
Cauldwell, E. W., Siekert, R. G., Lininger, R. E., and Anson, B. J. (1948). The bronchial arteries; an anatomic study of 150 human cadavers. Surg. Gynec. Obstet., 86, 395.

Darling, R. C., Rothney, W. B., and Craig, J. M. (1957). Total pulmonary venous drainage into the right side of the heart. Lab. Invest., 6, 44.

Edwards, J. E. (1960). In Pathology of the Heart, 2nd ed. S. E. Gould, p. 260. Thomas, Springfield, Illinois.

Freifeld, H., Schilowa, A., and Ludwinowsky, R. (1937). Die Heinzschen Körperchen und die Methämoglobinbildung bei Vergiftungen mit Amido- und Nitrobenzolverbindungen. Folia haemat. (Lpz.), 56, 333 .

Friedlich, A.. Bing, R. J., and Blount, S. G., Jr. (1950). Physiological studies in congenital heart disease. IX. Circulatory dynamics in the anomalies of venous return to the heart, including pulmonary arteriovenous fistula. Bull. Johns Hopk. Hosp., 86, 20

Gardner, D. L.., and Cole, L. (1955). Long survival with inferior vena cava draining into left atrium. Brit. Heart J., 17, 93 . Milzagenesie. Helv. paediat. Acta, 7, 369.

Gilbert, E. F., Nishimura, K., and Wedum, B. G. (1958). Congenital malformations of the heart associated with splenic agenesis. Circulation, 17, 72.

Gouley, B. A., and Gilbert, P. D. (1939). Left inferior vena cava. Arch. Path., 27, 1021.

Heinz, R. (1890). Morphologische Veränderungen der rothen Blutkörperchen durch Gifte. Virchows Arch. path. Anat., 122, 112.

$\mathrm{Hu}, \mathrm{C}$. H. (1929). Congenital malformation of heart with anomalous insertion of pulmonary veins, absence of spleen, situs inversus of abdominal viscera and other developmental errors. Report of a case. Amer. J. Path., 5, 389.

Hughes, C. W., and Rumore, P. C. (1944). Anomalous pulmonary veins. Arch. Path., 37, 364.

Keith, J. D., Rowe, R. D., and Vlad, P. (1958). Heart Disease in Infancy and Childhood. Macmillan, New York.

Laurence, K. M., and Brown, R. J. K. (1960). Total anomalous drainage of pulmonary veins into the left gastric vein. Brit. Heart J., 22, 295.

Leikin, S. L. (1951). Partial situs inversus with levocardia. Clin. Proc. Child. Hosp. (Wash.), 7, 236.

Martin, G. (1826). Observation d'une déviation organique de l'estomac, d'une anomalie dans la situation, dans la configuration du cœur er des vaisseaux qui en partent ou qui s'y rendent. Bull. Soc. anat. Paris, 1, 39.

Meadows, W. R., Bergstrand, I., and Sharp, J. T. (1961). Isolated anomalous connection of a great vein to the left atrium : The syndrome of cyanosis and clubbing, "normal" heart, and left ventricular hypertrophy on electrocardiogram. Circulation, 24. 669.

Muir, C. S. (1959). Splenic agenesis and multilobulate spleen. Arch. Dis. Childh., 34, 431.

Myers, B., and Keith, A. (1926). Case of congenital cyanosis. Proc roy. Soc. Med., 19, Clin. Sect., p. 43.

Pernkopf, E. (1926). Der partielle Situs inversus der Eingeweide beim Menschen. Z. Anat. Entwickl.-Gesch., 79, 577.

Pohl, J. C. (1740). Programma de defectu lienis et de liene in genere. In Disputationum anatomicarum Selectarum, 1748, Vol. 3, ed. A. Haller. Vandenhoeck, Gottingen.

Polhemus, D. W., and Schafer, W. B. (1952). Congenital absence of $\exists$ the spleen ; syndrome with atrioventricularis and situs inversus : case reports and review of the literature. Pediatrics, 9, 696.

- (1955). Congenital absence of the spleen. Ibid., 16, 495.

Putschar, W. G. J., and Manion, W. C. (1956). Congenital absence of the spleen and associated anomalies. Amer. J. clin. Path., 윽

Schilling-Torgau, V. (1912). “Kapselkörper” Pseudonukleoide. D Innenkörper, usw., sowie die Zentralkörperchengruppe in Säuget iererythrozyten. Folia haemat., 14, 129.

Stölker, C. (1864). Beitrag zur Pathologie der angebornen Stenose der Arteria pulmonalis. Schweiz. Z. Heilk., 3, 201.

Taussig, H. B. (1947). Clinical and pathological findings in cases of truncus arteriosus in infancy. Amer. $J$. Med, $2,26$.

Tobin, C. E. (1952). The bronchial arteries and their connections with other vessels in the human lung. Surg. Gynec. Obstet., 95, 741 .

Töndury, G. (1936). I'ber Situs inversus partialis des Duodenum. Z. Anat. Entwickl.-Gesch., 106, 251.

Venables, A. W. (1963). Isolated drainage of the inferior vena cava to the left atrium. Brit. Heart J., 25, 545.

Winslow, J. (1739). Cited by Darling et al., loc. cit.

Zadek, I., and Burg, K. (1930). Innenkör pe ranämien. Folia haemat. Lpz.), 41, 333 . 